\title{
LI33p53/FLp53 Predicts Poor Clinical Outcome in Esophageal Squamous Cell Carcinoma
}

This article was published in the following Dove Press journal:

Cancer Management and Research

\begin{abstract}
Qimin Tu (iD) ${ }^{1,2, *}$
Hongjian Gong (D) $3,4, *$

Chunhui Yuan ${ }^{3}$

Gao Liu $^{5}$

Jinqi Huang'

Zhichao $\mathrm{Li}^{4}$

Jianfei Luo ${ }^{2}$

'Department of Cardio-Thoracic Surgery, Central Hospital of Enshi Autonomous Prefecture, Enshi Clinical College of Wuhan University, Enshi, Hubei, People's Republic of China; ${ }^{2}$ Department of Gastrointestinal Surgery, Renmin Hospital of Wuhan University, Wuhan, Hubei, People's Republic of China; ${ }^{3}$ Clinical Research Center, Wuhan Medical and Health Center for Women and Children, Tongji Medical College, Huazhong University of Science and Technology, Wuhan, Hubei, People's Republic of China; ${ }^{4}$ Department of Rheumatism Immunology, Wuhan Medical and Health Center for Women and Children, Tongii Medical College, Huazhong University of Science and Technology, Wuhan, Hubei, People's Republic of China; ${ }^{5}$ Department of Gastrointestinal Surgery, Central Hospital of Enshi Autonomous Prefecture, Enshi Clinical College of Wuhan University, Enshi, Hubei, People's Republic of China
\end{abstract}

*These authors contributed equally to this work

Correspondence: Zhichao Li Department of Rheumatism Immunology, Wuhan Medical and Health Center for Women and Children, Tongji Medical

College, Huazhong University of Science and Technology, Wuhan, Hubei, People's Republic of China

Tel +86-27-82433423

Email linyuanmuchun@sina.com

Jianfei Luo

Department of Gastrointestinal Surgery, Renmin Hospital of Wuhan University,

Wuhan, Hubei, People's Republic of China

Tel +86-27-8804l9l I

Email afei099@I63.com
Background: p53 isoform $\Delta 133$ p53 is directly transactivated by p53 and antagonizes p53 activities in cancer progression. However, its correlation with prognosis and cancer recurrence in esophageal squamous cell carcinoma (ESCC) is still unclear.

Patients and Methods: Expression of $\Delta 133$ p53 and $\Delta 133$ p53/full-length p53 (FLp53) in tissues and serums of 180 ESCC patients was evaluated using qRT-PCR. Patients were divided into high- and low-expression groups according to the cutoff value determined by X-tile 3.6.1 software. Survival analysis was performed by the Kaplan-Meier method. Univariate and multivariate Cox survival analyses were applied to assess the hazard ratios (HRs).

Results: Tissue $\Delta 133$ p53 expression and $\Delta 133$ p53/FLp53 ratio were significantly increased in ESCC tissue compared with adjacent normal tissue. Pre-operative $\Delta 133 \mathrm{p} 53$ expression and $\Delta 133$ p53/FLp53 ratio in tissue or serum samples were positively associated with TNM stage and post-operative recurrence. Kaplan-Meier curve and multivariate cox regression analyses revealed that the tissue and serum $\Delta 133$ p53/FLp53 ratios (cutoff value: 2.9160 ) were independent prognostic factors for overall survival (OS) and progression-free survival (PFS) in ESCC patients and showed no statistical difference in receiver-operating characteristic curve (ROC) analysis, while serum $\Delta 133 \mathrm{p} 53$ showed no significant prognostic value. More importantly, the serum $\Delta 133$ p53/FLp53 ratio in ESCC patients was significantly decreased within $72 \mathrm{~h}$ post tumor resection and patients with a consistently high serum $\Delta 133$ p53/FLp53 ratio ( $\geq 2.9160)$ had higher recurrence rates than those with consistently low ratio values. In addition, dynamic detection in each follow-up timepoint showed that serum $\Delta 133$ p53/FLp53 ratios were higher than 2.9160 upon recurrence, and they even increased prior to radiologic progression.

Conclusion: The serum $\Delta 133$ p53/FLp53 ratio can be a novel predictor for survival outcome and may serve as a real-time parameter for monitoring recurrence in ESCC patients after surgery.

Keywords: esophageal squamous cell carcinoma, p53, $\Delta 133$ p53, prognosis, recurrence

\section{Introduction}

Esophageal cancer is the fourth leading cause of cancer-related death in both men and women in China, ${ }^{1}$ and approximately $90 \%$ of Chinese patients with esophageal cancer were diagnosed with esophageal squamous cell carcinoma (ESCC). ${ }^{2}$ Recently, multiple approaches have been developed to improve the outcome of ESCC, including esophagectomy combined with radiotherapy or chemotherapy. However, the 5-year overall survival rate is still inferior and ranges from 15 to $25 \%$ in all patients. ${ }^{3}$ This is thought to be due to a combination of late stage of diagnosis, rapid development of ESCC and lack of effective therapies. ${ }^{4}$ Moreover, molecular biomarkers capable of predicting 
recurrence and metastasis, which frequently developed in ESCC patients diagnosed with localized disease, have not yet been developed and thus treatment decisions regarding systemic therapy have been delayed.

Events involved in driving cancer evolution affect tumor aggressiveness, response to treatment and patient prognosis. ${ }^{5}$ To identify prognostic biomarkers, several recent large-scale genomic studies have characterized hundreds of somatic mutations, copy number alterations (CNAs) and structural variants (SVs) in ESCC. ${ }^{4,6-10}$ Mutations in SLC39A6, ${ }^{4}$ $\operatorname{EP} 300(10 \%),{ }^{9,10}$ and $F A M 135 B(6.8 \%)^{7}$ as well as amplification or overexpression of $E G F R^{5}$ were associated with a poor prognosis of ESCC. Moreover, many genes involved in cell cycle regulation, DNA repair and apoptosis were mutated or amplified in $99 \%$ of cases, including TP53 (93\%), CCND1 (33\%), CDK4/CDK6 (23.6\%), CDKN2A (20\%), NFE2L2 (10\%) and RB1 (9\%). ${ }^{7,9}$ As the highest frequency of mutated gene, mutation of TP53 in the DNA binding domain has been regarded as the main cause for $\mathrm{p} 53$ inactivation and proposed as a key factor in driving ESCC progression. ${ }^{9}$ Two compounds (ie, APR-246, COTI-2) that can reactivate missense-mutant $\mathrm{p} 53$ protein have been tested in clinical Phase I/II trials. ${ }^{11}$ However, a growing body of evidence has suggested that abundance of p53 isoforms in cancer tissues, due to alternative splicing or usage of alternative promoters, also modulates the biological processes regulated by full-length p53 (FLp53). ${ }^{12}$ Importantly, the tumor-promoting functions of p53 mutations also depend on the shorter p53 isoforms from the mutated FLp53 in some specific conditions, like missense mutations. ${ }^{13}$

The human $p 53$ gene encodes 12 natural p53 isoforms, including $\Delta 133 \mathrm{p} 53$, an N-terminally truncated isoform (lacking the first 132 amino acids). ${ }^{14} \Delta 133 p 53$ is directly transactivated by FLp53 in response to DNA-damaging signals and antagonizes p53 apoptotic activity. ${ }^{15}$ Furthermore, $\Delta 133$ p53 also stimulates angiogenesis, metastasis and generation of cancer stem cells regardless of p53 mutations, and its mRNA expression is associated with increased risk of recurrence and poor outcome in various cancers. ${ }^{16-20}$ Recently, several studies further clarified that elevated $\Delta 133 \mathrm{p} 53$ promotes an immunosuppressive and chemoresistant environment by inducing secretion of CCL-2, IL-6 and the recruitment of tumor-associated macrophages. ${ }^{21,22}$ Thus, $\Delta 133 \mathrm{p} 53$ isoform serves as an important oncogene by antagonistically modulating p53 functions. ${ }^{23,24}$ Previously, we have demonstrated that $\Delta 133$ p53 promotes DNA double-strand break (DSB) repair and tumorigenesis by coordinating with p73 in a p53independent manner; ${ }^{12,25}$ however, the expression level of
$\Delta 133 p 53$ and its prognostic performance in ESCC remains unknown.

In the present study, we first measured the levels of $\Delta 133$ p53 and p53 and calculated their ratio $(\Delta 133 p 53 /$ FLp53) in cancerous tissue compared to adjacent normal tissues; subsequently, we analyzed their prognostic value in ESCC patients undergoing tumor resection. Circulating p53 mutations were significantly associated with drug resistance and disease progression of patients with metastatic breast cancer. ${ }^{26}$ Based on promising results in the tissue, we further investigated dynamic changes and prognostic significance of the serum $\Delta 133$ p53/FLp53 ratio in ESCC patients.

\section{Patients and Methods}

\section{Patients and Samples}

FFPE cancerous tissue samples and parallel serum samples of 180 ESCC patients with overall survival information were collected from the Central Hospital of Enshi Autonomous Prefecture (China) between January 2009 to December 2012. All cases were pathologically confirmed as ESCC and did not receive chemotherapy and radiotherapy before tumor resection. Serum samples were obtained before and within 72 $\mathrm{h}$ following surgery, and then stored at $-80^{\circ} \mathrm{C}$ for further use. FFPE tissue samples were obtained at the time of surgery and adjacent normal tissue samples were also collected from 42 of 180 ESCC patients. Due to the fact that 31 patients had no regular follow-up checks for recurrence or progression after surgery (confirmed by CT scan), 149 in 180 ESCC patients with recurrence information were included for PFS analysis. Patient clinical information, including age, gender, BMI, smoking, clinicopathological features (tumor location, TNM and differentiation stage) were obtained from the clinical or pathologic records. All cases of ESCC were staged based on the 7th edition of the AJCC/UICC TNM classification system. This study was approved by the Ethics Committee of Central Hospital of Enshi Autonomous Prefecture. All participants were informed about the purpose, procedures, benefits and potential risks of the study, and their written or oral consents (if patients are without culture, or culture is very shallow, the informed oral consent process was approved by the Ethics Committee of the Central Hospital of Enshi Autonomous Prefecture) were obtained.

\section{RNA Isolation and cDNA Synthesis}

Five 8- $\mu \mathrm{m}$-thick FFPE tissue samples were cut from each block and placed in sterile $1.5-\mathrm{mL}$ centrifuge tubes ready 
for extraction. Total RNA was extracted using an RNAprep Pure FFPE Kit (TIANGEN Biotech, Beijing, China) according to the manufacturer's instructions. Total RNA of $300 \mu \mathrm{L}$ serum was isolated by using a Liquid Total RNA Isolation Kit (BioTeke, Beijing, China) as we described previously ${ }^{27}$ and treated with DNase I prior to reverse transcription. The concentration of RNA was measured by Nanodrop 2000 spectrophotometer (Thermo Fisher) following purification with RNeasy mini kit (QIAGEN). First strand cDNA was synthesized using M-MLV Reverse Transcriptase (Invitrogen) and conditions were as follows: $65^{\circ} \mathrm{C}$ for $5 \mathrm{~min}$, and then $37^{\circ} \mathrm{C}$ for 50 $\min , 70^{\circ} \mathrm{C}$ for $15 \mathrm{~min}$.

\section{Quantitative Real-Time PCR (qRT-PCR)}

The expressions of $\Delta 133$ p53 and full-length p53 (FLp53) were determined on the ABI-7300 (Thermo Fisher) using Maxima SYBR Green/ROX qPCR Master Mix (Thermo Fisher Scientific) according to the manufacturer's instructions. The primers used were as follows: $\Delta 133$ p53 (GenBank accession No. NM_001126115.1) ${ }^{15}$ (Forward: 5'-TGGGTTGCAGGAG GTGCTTAC-3', Reverse: 5'-CCACTCGGATA AGATGCT GAGG-3'), FLp53 (Forward: 5'-GCTCAAGACTGGCGCT AAA-3', Reverse: 5'-GTTTTCA GGAAGTAGTTTCCAT AGG-3'), and GAPDH (Forward: 5'-GAGTCAACGGATTT GGTCGTAT-3', Reverse: 5'-ATGGGTGGAATCATATTGG AAC- $3^{\prime}$ ) was used as the endogenous control. ${ }^{28}$ The reactions were started at $95^{\circ} \mathrm{C}$ for $5 \mathrm{~min}$, followed by 42 cycles of $95^{\circ} \mathrm{C}$ for $30 \mathrm{~s}, 59.3^{\circ} \mathrm{C}$ for $30 \mathrm{~s}$, and $72^{\circ} \mathrm{C}$ for $30 \mathrm{~s}$. All experiments were carried out in triplicate for each data point. Relative quantification of $\Delta 133 \mathrm{p} 53$ and FLp53 expression was calculated with the $2^{-\Delta \mathrm{Ct}}$ method.

\section{Statistical Analysis}

SPSS software (version 17.0; USA) and Graphpad Prism software (version V.5.00, USA) were used to perform the statistical analyses in this study. Differences in the $\Delta 133 \mathrm{p} 53$ / FLp53 ratio between ESCC and paired adjacent normal tissues were compared using a paired Student's $t$-test. Patients were divided into relatively high- and low-expression groups according to the cutoff value determined by X-tile 3.6.1 software (Yale University, New Haven, CT, USA) ${ }^{29}$ in serum and tissue samples for survival analysis. The $\chi^{2}$ test or Fisher's exact test was used to determine the correlations of $\Delta 133 \mathrm{p} 53$ / FLp53 in tissue or serum samples with the clinicopathological factors of ESCC patients. Pearson's correlation coefficient analysis was used to determine the association of the $\Delta 133$ p53/FLp53 ratio in the tissue and in the serum.
Survival analysis was carried out by the Kaplan-Meier method, and subjected to the log rank test. Univariate and multivariate Cox survival (Forward Stepwise Likelihood Ratio method) analyses were applied to assess the hazard ratios (HRs). For the Cox proportional hazards regression model, all covariate, including age, gender, BMI, smoking history, tumor location, pathologic $\mathrm{M}, \mathrm{N}$ and $\mathrm{T}$ stage, grade, recurrence, tissue $\Delta 133 \mathrm{p} 53 / \mathrm{p} 53$ ratio and serum $\Delta 133 \mathrm{p} 53 / \mathrm{p} 53$ ratio were treated as binary variable and adjusted for the multivariate Cox proportional hazard regression model on tissue and serum $\Delta 133 \mathrm{p} 53 / \mathrm{p} 53$ ratio. $P<0.05$ was considered statistically significant. Receiver operating characteristic (ROC) curve analysis was conducted by MedCalc statistical software (Version 18.11.6, USA) to determine the predictive value of the parameters.

\section{Results}

\section{$\Delta I 33 p 53$ and $\Delta I 33 p 53 / F L p 53$ Ratio Significantly Increased in ESCC Tissues}

As there is no specific antibody for the $\Delta 133 \mathrm{p} 53$ isoform, ${ }^{30}$ we first examined the mRNA abundance of $\Delta 133 \mathrm{p} 53$ in 42 pairs of tumor and adjacent normal tissues to determine whether $\Delta 133$ p53 was associated with ESCC progression. $\Delta 133$ p53 isoform significantly increased in cancerous tissues $(0.10 \pm 0.09$ vs $0.05 \pm 0.03, P=0.0019)$ (Figure 1A). We simultaneously detected mRNA expression of FLp53 in these paired samples and confirmed that FLp53 is significantly decreased in cancerous tissues of ESCC patients $(0.06$ \pm 0.04 vs $0.17 \pm 0.14, P<0.0001$ ) (Figure $1 \mathrm{~B}$ ). In addition, we also noticed that the expression ratio of $\Delta 133 \mathrm{p} 53$ to FLp53 significantly increased in cancerous tissues $(2.40 \pm$ 3.16 vs $0.50 \pm 0.64, P=0.0006$ ) (Figure $1 C$ ).

\section{Elevated Tissue $\Delta$ I33p53/FLp53 Ratio Predicts Poor Outcome of ESCC Patients}

To confirm the association of $\Delta 133$ p53 and FLp53 with clinical outcomes of ESCC patients, we then measured $\Delta 133 \mathrm{p} 53$ and FLp53 expression in 180 FFPE ESCC tissue samples. The optimal cut-off values of $\Delta 133 p 53$, FLp53 and $\Delta 133 p 53 /$ FLp53 ratio for predicting the prognosis of ESCC were estimated by X-tile 3.6.1 software (Figure S1). ESCC patients were divided into two groups $(\Delta 133 \mathrm{p} 53<0.0425$ and $\geq 0.0425$; FLp53 $<0.0195$ and $\geq 0.0195 ; \Delta 133$ p53/FLp53 ratio $<2.6470$ and $\geq 2.6470$ ). The clinicopathological characteristics of the ESCC patients divided by the cut-off values of $\Delta 133 \mathrm{p} 53$, FLp53 and $\Delta 133$ p53/FLp53 ratio are shown in Table 1. Our results indicated that the elevated $\Delta 133 \mathrm{p} 53$ was significantly 
A

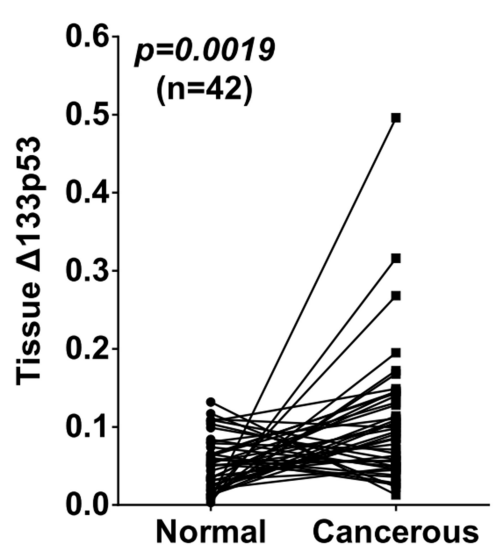

D

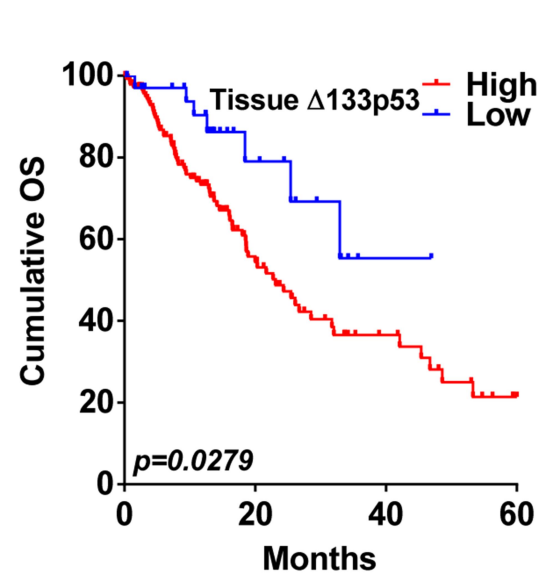

G

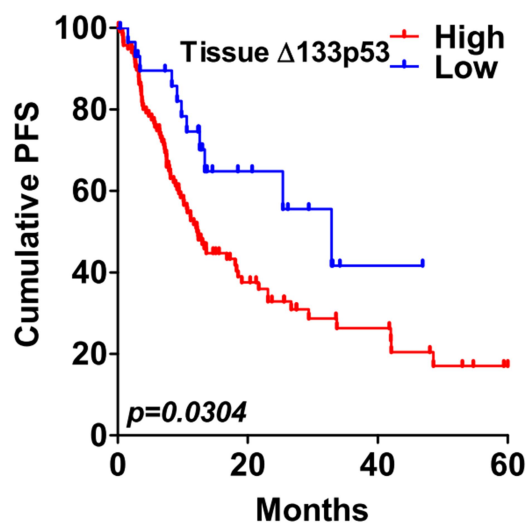

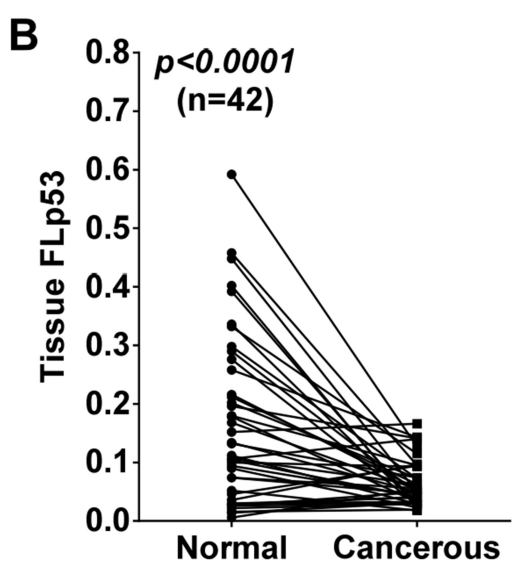

E

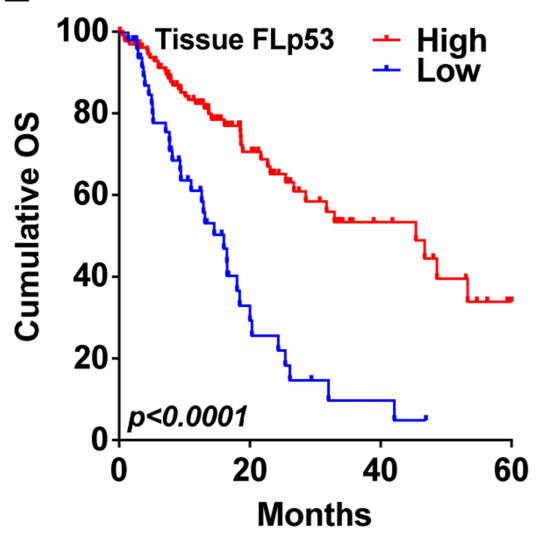

H

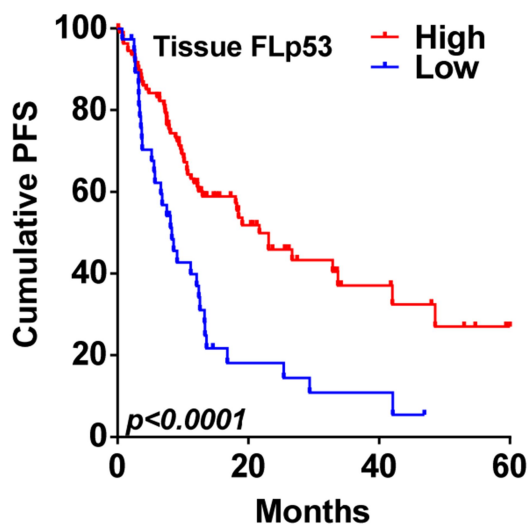

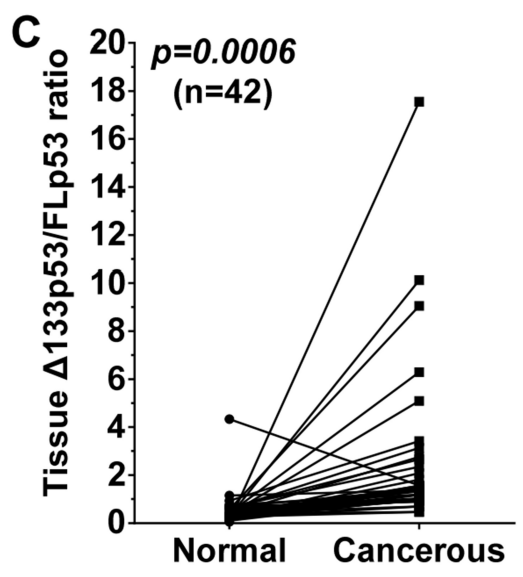

F

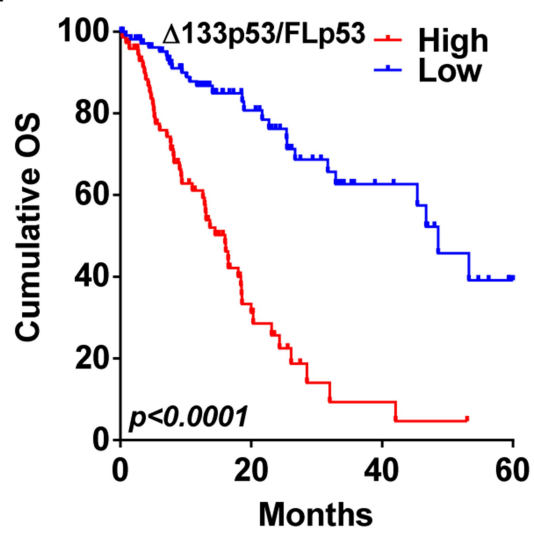

I

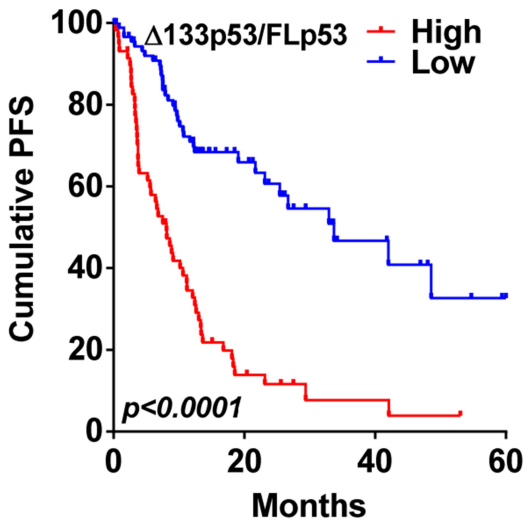

Figure I Kaplan-Meier curves of tissue $\Delta \mathrm{I} 33 \mathrm{p} 53$, FLp53 and $\Delta \mathrm{I} 33 \mathrm{p} 53 / \mathrm{FL} 553$ ratio in ESCC. mRNA expression of $\Delta \mathrm{I} 33 \mathrm{p} 53$ (A), FLp53 (B) and $\Delta \mathrm{I} 33 \mathrm{p} 53 / \mathrm{FL} 53$ ratio (C) in 42 paired adjacent normal and cancerous tissue of ESCC patients. ESCC, esophageal squamous cell carcinoma; FLp53, full-length p53. OS of I80 ESCC patients divided by tissue $\Delta \mathrm{I} 33 \mathrm{p} 53$ (D), FLp53 (E) and $\Delta \mathrm{I} 33$ p53/FLp53 ratio (F). PFS of I49 ESCC patients divided by tissue $\Delta \mathrm{I} 33 \mathrm{p} 53$ (G), FLp53 (H) and $\Delta \mathrm{I} 33 \mathrm{p} 53 / \mathrm{FL} 553$ ratio (I).

Abbreviations: OS, overall survival; PFS, progression-free survival.

associated with increased TNM stage $(P=0.0011)$, differentiation grade $(P=0.0030)$ and recurrence $(P=0.0371)$, although it had no significant correlations with other clinicopathological features such as age, gender, and BMI index (Table 1). Decreased FLp53 was significantly associated with male gender $(P=0.0166)$, higher BMI $(P=0.0078)$, lower tumor location $(P=0.0295)$, increased TNM stage $(P<$ $0.0001)$, differentiation grade $(P<0.0001)$ and recurrence $(P<0.0001)$ (Table 1$)$. Increased $\Delta 133$ p53/FLp53 ratio was significantly associated with Lower tumor location $(P=0.0091)$, increased TNM stage $(P<0.0001)$, differentiation grade $(P<0.0001)$ and recurrence $(P<0.0001)$ (Table 1$)$. 
Table I Associations of Tissue $\Delta / 33 p 53, p 53$ and $\Delta / 33 p 53 / p 53$ Ratio with Clinicopathological Features in ESCC

\begin{tabular}{|c|c|c|c|c|c|c|c|c|c|}
\hline & \multicolumn{3}{|l|}{$\Delta 133 p 53$} & \multicolumn{3}{|l|}{ p53 } & \multicolumn{3}{|c|}{$\Delta 133$ p53/p53 ratio } \\
\hline & $<0.0425$ & $\geq 0.0425$ & $P$ value & $<0.0195$ & $\geq 0.0195$ & $P$ value & $<2.6470$ & $\geq 2.6470$ & $P$ value \\
\hline Age & & & 0.3944 & & & 0.6353 & & & 0.1389 \\
\hline$<60$ & 18 & 63 & & 23 & 58 & & 53 & 28 & \\
\hline$\geq 60$ & 17 & 82 & & 25 & 74 & & 54 & 45 & \\
\hline Gender & & & 1.0000 & & & 0.0166 & & & 0.1375 \\
\hline Male & 30 & 124 & & 46 & 108 & & 88 & 66 & \\
\hline Female & 5 & 21 & & 2 & 24 & & 19 & 7 & \\
\hline BMI & & & 0.4820 & & & 0.0078 & & & 0.4763 \\
\hline$<24$ & 17 & 80 & & 18 & 79 & & 60 & 37 & \\
\hline$\geq 24$ & 18 & 65 & & 30 & 53 & & 47 & 36 & \\
\hline Smoking history & & & 0.8146 & & & 1.0000 & & & 0.3624 \\
\hline No & 6 & 30 & & 9 & 27 & & 19 & 17 & \\
\hline Yes & 29 & 115 & & 39 & 105 & & 88 & 56 & \\
\hline Tumor location & & & 0.9731 & & & 0.0295 & & & 0.0091 \\
\hline Upper/Middle & 11 & 46 & & 9 & 48 & & 42 & 15 & \\
\hline Lower & 24 & 99 & & 39 & 84 & & 65 & 58 & \\
\hline Pathologic M & & & 0.1304 & & & $<0.000$ I & & & $<0.0001$ \\
\hline Mo & 34 & 126 & & 32 & 128 & & 106 & 54 & \\
\hline MI & 1 & 19 & & 16 & 4 & & 1 & 19 & \\
\hline Pathologic N & & & 0.4211 & & & $<0.0001$ & & & $<0.0001$ \\
\hline No-NI & 32 & 122 & & 32 & 122 & & 106 & 48 & \\
\hline N2-N3 & 3 & 23 & & 16 & 10 & & 1 & 25 & \\
\hline Pathologic T & & & 0.0662 & & & 0.0009 & & & $<0.0001$ \\
\hline TI-T2 & 20 & 58 & & 11 & 67 & & 67 & II & \\
\hline T3-T4 & 15 & 87 & & 37 & 65 & & 40 & 62 & \\
\hline TNM stage & & & 0.0011 & & & $<0.000$ I & & & $<0.0001$ \\
\hline I-II & 28 & 71 & & 6 & 93 & & 98 & I & \\
\hline III-IV & 7 & 74 & & 42 & 39 & & 9 & 72 & \\
\hline Grade & & & 0.0030 & & & $<0.000$ I & & & $<0.0001$ \\
\hline GI-G2 & 24 & 59 & & 9 & 74 & & 71 & 12 & \\
\hline G3-G4 & II & 86 & & 39 & 58 & & 36 & 61 & \\
\hline Recurrence $^{a}$ & & & 0.0371 & & & $<0.0001$ & & & $<0.0001$ \\
\hline No & 23 & 65 & & 10 & 78 & & 73 & 15 & \\
\hline Yes & 7 & 54 & & 28 & 33 & & 18 & 43 & \\
\hline
\end{tabular}

Note: ${ }^{\text {a }} 149$ of 180 patients with regular follow-up checks for recurrence after surgery.

The median survival time of all patients was 25.47 months (range 0.3-60 months), 106 patients (58.89\%) were censored and 74 patients $(41.11 \%)$ died during our follow-up period. Kaplan-Meier analysis revealed that increased tissue abundance of $\Delta 133 \mathrm{p} 53\left(\chi^{2}=4.83, P=0.0279\right)$ (Figure 1D) and decreased p53 expression $\left(\chi^{2}=27.76, P<0.0001\right)$ (Figure $1 \mathrm{E})$, as well as increased $\Delta 133$ p53/FLp53 ratio $\left(\chi^{2}=42.34\right.$, $P<0.0001$ ) (Figure 1F) were significantly related to worse
OS. By the time of analysis, 149 of 180 ESCC patients had regular follow-up checks for recurrence after surgery. Recurrence occurred in 61 of 149 patients, with a median follow-up time of 13.4 months (range 0.8-42 months), and 88 patients had clear evidence of no recurrence. Tissue $\Delta 133 p 53$ and $\Delta 133 p 53 / F L p 53$ ratio were significantly increased in recurrent patients compared with non-recurrent ones ( $P=0.0032$ and $P<0.0001$, respectively), and FLp53 
was decreased in recurrent patients $(P=0.0023)$ (Figure S2). Kaplan-Meier analysis revealed that increased $\Delta 133 \mathrm{p} 53$ $\left(\chi^{2}=4.69, P=0.0304\right)$ (Figure 1G), decreased $\mathrm{p} 53$ expression $\left(\chi^{2}=15.53, P<0.0001\right)($ Figure $1 \mathrm{H})$ and increased $\Delta 133 \mathrm{p} 53 /$ FLp53 ratio $\left(\chi^{2}=39.18, P<0.0001\right)$ (Figure 1I) were significantly associated with worse PFS. Thus, these results demonstrate that tissue $\Delta 133$ p53 and FLp53 expression, tissue $\Delta 133$ p53/FLp53 ratio are associated with OS and PFS of ESCC patients.

\section{Serum $\Delta$ I33p53/FLp53 Ratio Shows Prognostic Significance in ESCC Patients} p53 could exist as circulating DNA or mRNA in cancers, ${ }^{28,31}$ we next further evaluated $\Delta 133 \mathrm{p} 53$ and FLp53 mRNA expression in serum of 180 ESCC patients. Pearson's correlation coefficient analysis revealed that serum $\Delta 133$ p53, FLp53 and $\Delta 133$ p53/FLp53 ratio were positively correlated with their tissue expression, and Pearson's correlation coefficients were $0.7019(P<$ $0.0001)$ (Figure 2A), $0.4030(P<0.0001)$ (Figure 2B) and $0.4137(P<0.0001)$ (Figure $2 \mathrm{C})$, respectively. ESCC patients were divided into two groups $(\Delta 133 \mathrm{p} 53<0.0870$ and $\geq 0.0870 ;$ FLp53 $<0.0300$ and $\geq 0.0300 ; \Delta 133 p 53 /$ FLp53 ratio $<2.9160$ and $\geq 2.9160$ ) by X-tile 3.6.1 software (Figure S3). Correlation analysis revealed that the elevated serum $\Delta 133$ p53 was significantly associated with male gender $(P=0.0105)$, increased $\mathrm{M}$ stage $(P=0.0086)$, $\mathrm{N}$ stage $(P=0.0184)$ and TNM stage $(P=0.0008)$, as well as recurrence $(P=0.0005)$ (Table 2$)$. Increased $\triangle 133$ p53/FLp53 ratio was significantly associated with high BMI index $(P=0.0287)$, increased $\mathrm{M}$ stage $(P<$ $0.0001)$, N stage $(P=0.0133)$, TNM stage $(P<0.0001)$, differentiation grade $(P=0.0131)$ and recurrence $(P<$ 0.0001) (Table 2). Whereas decreased serum FLp53 was only associated with increased TNM stage $(P=0.0276)$ and recurrence $(P=0.0007)$ (Table 2).

Serum $\Delta 133 p 53$ and $\Delta 133$ p53/FLp53 ratio were significantly increased in recurrent patients compared with nonrecurrent ones $(P=0.0002$ and $P<0.0001$, respectively) (Figure S4A and $\underline{\mathrm{S} 4 \mathrm{C}}$ ), FLp53 was decreased in recurrent patients $(P=0.0001)$ (Figure S4B). However, survival analysis indicated that increased serum $\Delta 133 \mathrm{p} 53$ showed no association with $\mathrm{OS}\left(\chi^{2}=2.89, P=0.0890\right)$ (Figure 2D) and PFS $\left(\chi^{2}=2.93, P=0.0871\right)$ (Figure 2E). Decreased p53 expression correlated with decreased OS $\left(\chi^{2}=5.80, P=0.0160\right)$ (Figure $2 \mathrm{~F}$ ) and PFS $\left(\chi^{2}=10.27, P=0.0014\right.$ ) (Figure $2 \mathrm{G}$ ); and increased $\Delta 133$ p53/FLp53 ratio correlated with poor OS $\left(\chi^{2}=17.26, P<0.0001\right)($ Figure $2 \mathrm{H})$ and PFS $\left(\chi^{2}=56.16, P<\right.$ 0.0001) (Figure 2I). Taken together, these results suggest that serum FLp53 expression and $\Delta 133$ p53/FLp53 ratio are associated with OS and PFS of ESCC patients.

\section{Tissue and Serum $\Delta$ I33p53/FLp53 Ratios are Poor Independent Prognostic Factors for ESCC}

The univariate survival analysis indicated that tissue and serum $\Delta 133$ p53/FLp53 ratio were correlated with OS (Table 3) and PFS (Table 4) of ESCC patients. Furthermore, the multivariate analyses identified that the tissue $\Delta 133 \mathrm{p} 53 /$ FLp53 ratio was an independent prognostic factor for OS $(\mathrm{HR}=3.864 ; 95 \% \mathrm{CI}=2.293-6.511, P<0.0001)$ (Table 3$)$ and PFS (HR $=2.283 ; 95 \% \mathrm{CI}=1.387-3.760, P<0.0001)$ (Table 4) of ESCC patients. The serum $\Delta 133$ p53/FLp53 ratio was also an independent prognostic factor for OS (HR = 2.503; 95\% CI $=1.465-4.276, P=0.0011$ ) (Table 3) and PFS (HR $=3.230 ; 95 \% \mathrm{CI}=1.947-5.359, P<0.0001)$ (Table $3)$ of ESCC patients. Besides, $M$ stage and recurrence were also predictive indicators for OS and PFS. However, serum $\Delta 133$ p53 or FLp53 and tissue $\Delta 133$ p53 were not independent prognostic factors for OS and PFS of ESCC patients, except tissue FLp53 (data not shown).

\section{Tissue and Serum $\Delta$ I33p53/FLp53 Ratios Show No Difference in Prognostic Performance for OS and PFS}

We also conducted a ROC analysis of tissue and serum $\Delta 133$ p53/FLp53 ratio. The AUC values of tissue and serum $\Delta 133$ p53/FLp53 ratio in the Cox regression model for OS were $0.695(P=0.0351)$ and $0.641(P=0.0360)$, respectively (Figure 3A), and $0.692(P=0.0337)$ and $0.649(P=0.0340)$ for PFS, respectively (Figure 3B). Prognostic performance of tissue and serum $\Delta 133 \mathrm{p} 53 /$ FLp53 ratio showed no statistical difference for OS and PFS $(P=0.2066$ and $P=0.3207$, respectively).

\section{The Dynamic Change of Serum $\Delta$ I33p53/ FLp53 Ratio After Surgery and Its Association with Recurrence}

To evaluate whether serum $\Delta 133$ p53/FLp53 ratio dynamically correlates with treatment response, we further measured its postoperative level in 180 ESCC patients within $72 \mathrm{~h}$ after resection. Postoperative serum $\Delta 133 \mathrm{p} 53 /$ FLp53 ratio significantly dropped after surgery $(4.31 \pm 7.69$ vs 


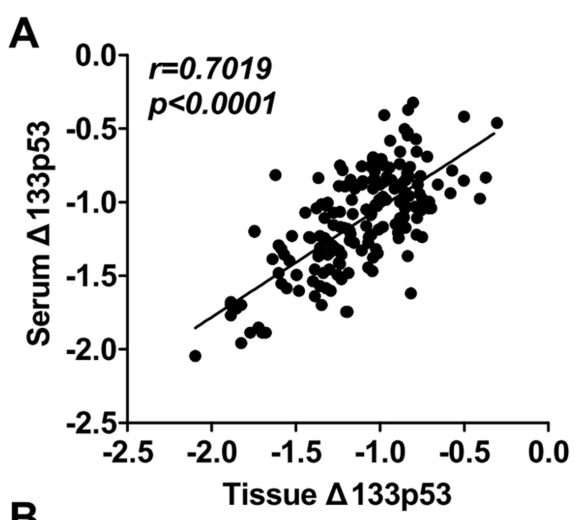

B
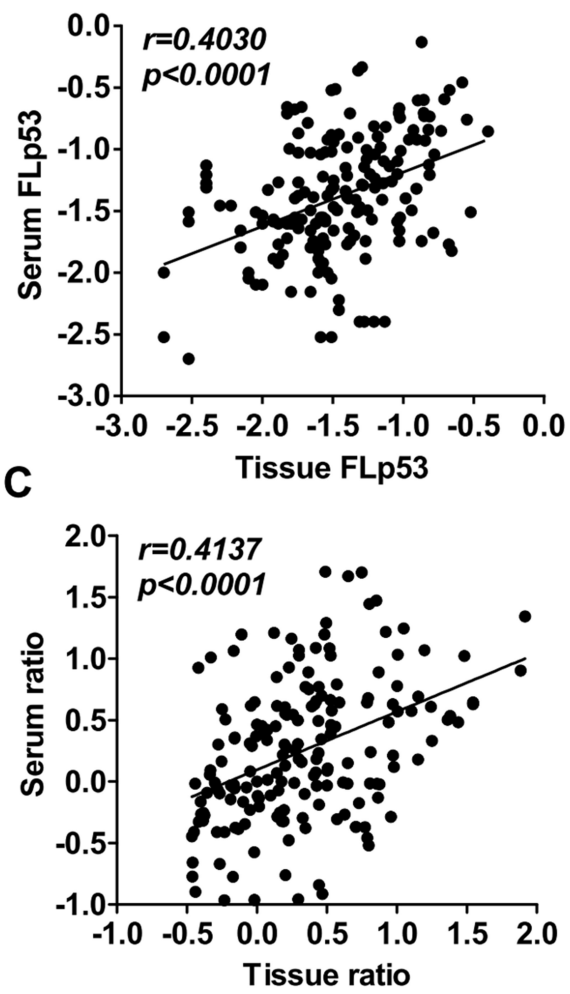

D

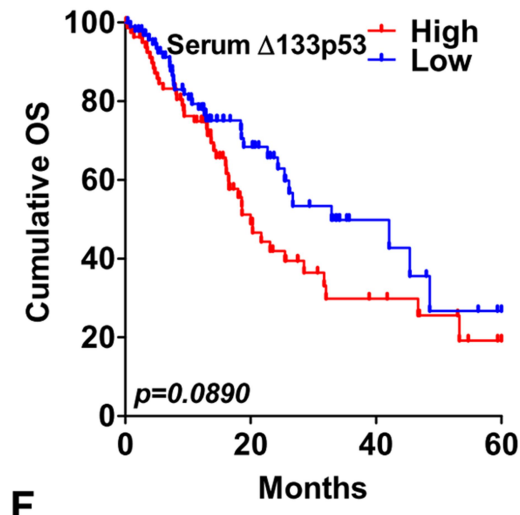

$\mathbf{F}$
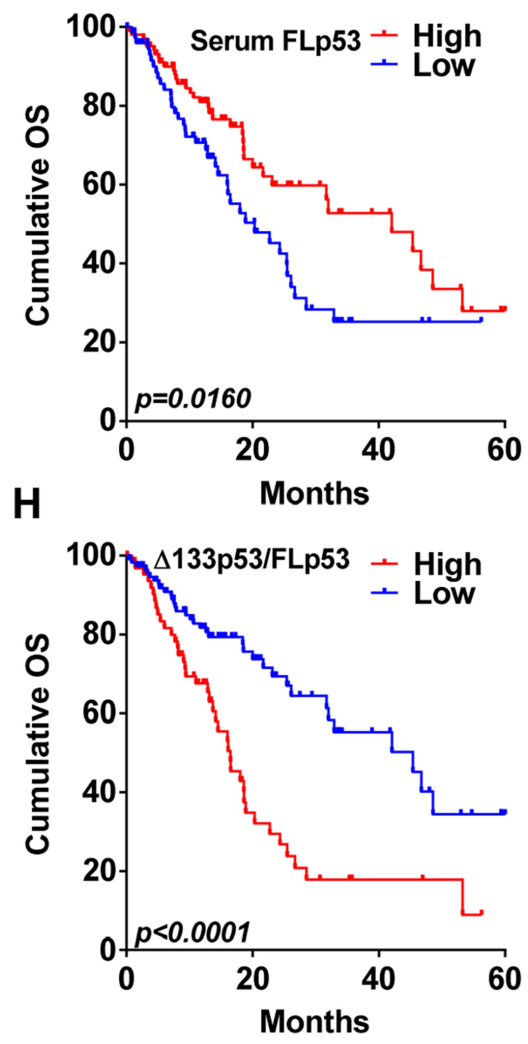

E

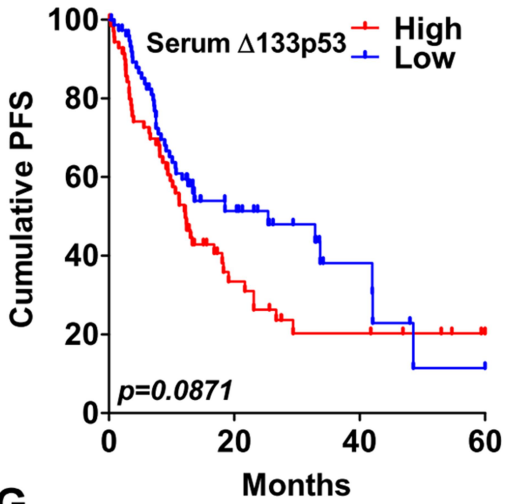

G
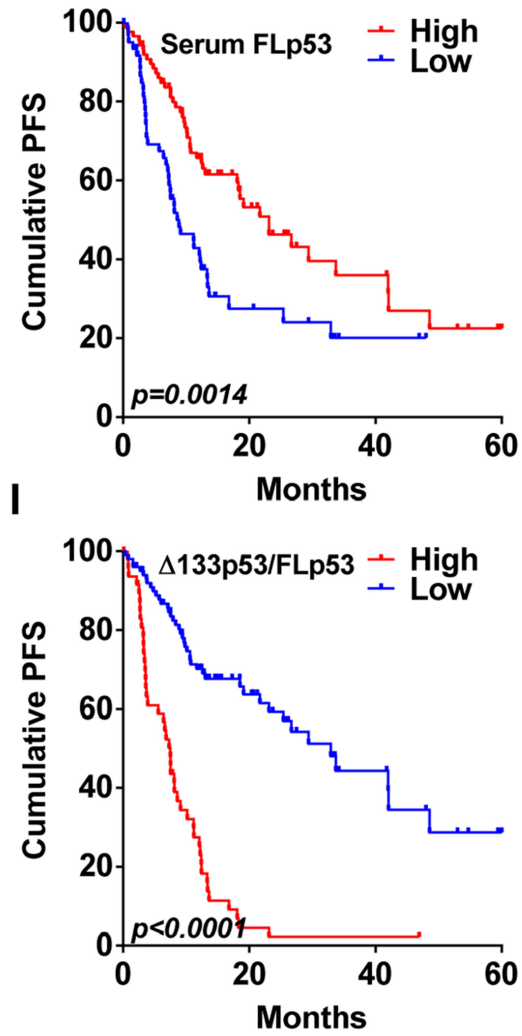

Figure 2 Kaplan-Meier curves of serum $\Delta \mathrm{I} 33 \mathrm{p} 53$, FLp53 and $\Delta \mathrm{I} 33 \mathrm{p} 53 / \mathrm{FL} 553$ ratio in ESCC. Pearson's correlation analysis between tissue $\Delta \mathrm{I} 33 \mathrm{p} 53$ (A), FLp53 (B), $\Delta$ I33p53/FLp53 ratio (C) and their respective level in serum of ESCC patients. OS of I80 ESCC patients divided by preoperative serum $\Delta \mathrm{I} 33$ p53 (D), FLp53 (F) and $\Delta$ I33p53/FLp53 ratio (H). PFS of I49 ESCC patients divided by preoperative serum $\Delta$ I33p53 (E), FLp53 (G) and $\Delta$ I33p53/FLp53 ratio (I).

$2.81 \pm 4.12, P=0.0098$ ) (Figure 4A). Based on changes between preoperative and postoperative serum $\Delta 133 \mathrm{p} 53 /$ FLp53 ratio, patients were divided into four groups: I, persistent high levels at the two time points; II, preoperative high followed by postoperative low; III, preoperative low followed by postoperative high, and IV, preoperative low followed by postoperative low, using the same cutoff value of preoperative serum $\Delta 133 \mathrm{p} 53 / \mathrm{FLp} 53$ ratio (2.9160). Persistent high levels of serum $\Delta 133$ p53/FLp53 ratio predicted poor OS (Figure 4B), higher recurrence rates (Figure 4C) and worse PFS (Figure 4D) in ESCC patients. Patients in group I showed significantly shorter time to relapse (TTR) and higher recurrence rates than group IV (median TTR of 5.57 months vs not reached; recurrence of $27 / 28$ vs $14 / 88, P<0.0001$ ), as well as group III (median TTR of 5.57 months vs 29.4 months; recurrence of $27 / 28$ vs $4 / 13, P<0.0001$ ), while there was a propensity of increased recurrence compared with group II (median TTR of 5.57 months vs 8.07 months; recurrence of $27 / 28$ vs $16 / 20 ; P=0.0643$ ) (Figure $4 \mathrm{C}$ ). 
Table 2 Associations of Serum $\Delta / 33 p 53, p 53$ and $\Delta / 33 p 53 / p 53$ Ratio with Clinicopathological Features in ESCC

\begin{tabular}{|c|c|c|c|c|c|c|c|c|c|}
\hline & \multicolumn{3}{|l|}{$\Delta 133 p 53$} & \multicolumn{3}{|l|}{ p53 } & \multicolumn{3}{|c|}{$\Delta$ 133p53/p53 Ratio } \\
\hline & $<0.0870$ & $\geq 0.0870$ & $P$ value & $<0.0300$ & $\geq 0.0300$ & $P$ value & $<2.9160$ & $\geq 2.9160$ & $P$ value \\
\hline Age & & & 0.5088 & & & 0.9394 & & & 0.5852 \\
\hline$<60$ & 41 & 40 & & 34 & 47 & & 50 & 31 & \\
\hline$\geq 60$ & 55 & 44 & & 41 & 58 & & 65 & 34 & \\
\hline Gender & & & 0.0105 & & & 0.1322 & & & 0.0759 \\
\hline Male & 76 & 78 & & 68 & 86 & & 94 & 60 & \\
\hline Female & 20 & 6 & & 7 & 19 & & 21 & 5 & \\
\hline BMI & & & 0.9363 & & & 0.0516 & & & 0.0287 \\
\hline$<24$ & 52 & 45 & & 34 & 63 & & 69 & 28 & \\
\hline$\geq 24$ & 44 & 39 & & 41 & 42 & & 46 & 37 & \\
\hline Smoking history & & & 0.2320 & & & 0.7055 & & & 0.6981 \\
\hline No & 16 & 20 & & 14 & 22 & & 24 & 12 & \\
\hline Yes & 80 & 64 & & 61 & 83 & & 91 & 53 & \\
\hline Tumor location & & & 0.2748 & & & 0.2229 & & & 0.5974 \\
\hline Upper/Middle & 27 & 30 & & 20 & 37 & & 38 & 19 & \\
\hline Lower & 69 & 54 & & 55 & 68 & & 77 & 46 & \\
\hline Pathologic M & & & 0.0086 & & & 0.2331 & & & $<0.0001$ \\
\hline Mo & 91 & 69 & & 64 & 96 & & 112 & 48 & \\
\hline MI & 5 & 15 & & II & 9 & & 3 & 17 & \\
\hline Pathologic N & & & 0.018 & & & 0.0870 & & & 0.0133 \\
\hline No-NI & 88 & 66 & & 60 & 94 & & 104 & 50 & \\
\hline N2-N3 & 8 & 18 & & 15 & 11 & & 11 & 15 & \\
\hline Pathologic T & & & 0.1035 & & & 0.2856 & & & 0.3214 \\
\hline TI-T2 & 47 & 31 & & 29 & 49 & & 53 & 25 & \\
\hline T3-T4 & 49 & 53 & & 46 & 56 & & 62 & 40 & \\
\hline TNM stage & & & 0.0008 & & & 0.0276 & & & $<0.0001$ \\
\hline I-II & 64 & 35 & & 34 & 65 & & 78 & 21 & \\
\hline III-IV & 32 & 49 & & 41 & 40 & & 37 & 44 & \\
\hline Grade & & & 0.0857 & & & 0.4333 & & & 0.0131 \\
\hline GI-G2 & 50 & 33 & & 32 & 51 & & 61 & 22 & \\
\hline G3-G4 & 46 & 51 & & 43 & 54 & & 54 & 43 & \\
\hline Recurrence ${ }^{a}$ & & & 0.0005 & & & 0.0007 & & & $<0.0001$ \\
\hline No & 56 & 32 & & 26 & 62 & & 83 & 5 & \\
\hline Yes & 21 & 40 & & 35 & 26 & & 18 & 43 & \\
\hline
\end{tabular}

Note: ${ }^{\text {a }} 149$ of 180 patients with regular follow-up checks for recurrence after surgery.

Compared with group IV, patients in groups I and II had significantly shorter TTR and higher recurrence rates (all $P<0.0001$, Figure 4C).

Twelve patients with no history of radio- or chemotherapies after tumor resection were selected for measurement of real-time changes of serum $\Delta 133$ p53/FLp53 ratio in each time of follow-up (tumor recurrence was monitored by CT scans every 4 months in the first two years). Six patients were confirmed to have lung, brain or lymph node metastasis, and the other 6 showed no evidence of recurrence. The serum $\Delta 133$ p53/FLp53 ratios were higher than 2.9160 at the time of detected recurrence in 6 patients and even increased prior to radiologic progression in 2/6 patients, while they were lower than 2.9160 in $4 / 6$ patients with no recurrence (Figure 4E). In addition, healthy donors exhibited significantly lower serum $\Delta 133$ p53/FLp53 ratios than did ESCC patients preoperatively, mostly lower than 2.9160 (Figure S4D). The best cutoff value of the serum $\Delta 133$ p53/FLp53 ratio to distinguish 
Table 3 Univariate and Multivariate Survival Analyses of OS in Patients with ESCC

\begin{tabular}{|c|c|c|c|c|}
\hline & \multicolumn{2}{|l|}{ Univariate Analysis } & \multicolumn{2}{|c|}{ *Multivariate Analysis } \\
\hline & HR $(95 \% \mathrm{Cl})$ & $P$ value & HR $(95 \% \mathrm{Cl})$ & $P$ value \\
\hline Age $(\geq 60$ vs $<60)$ & I.203 (0.758-I.908) & 0.4332 & & \\
\hline Gender (Male vs Female) & $2.012(0.873-4.64 I)$ & 0.100 & & \\
\hline BMI $(\geq 24$ vs $<24)$ & I.I88 (0.750-I.882) & 0.4624 & & \\
\hline Smoking history (Yes vs No) & $1.618(0.923-2.836)$ & 0.0931 & & \\
\hline Tumor location (Lower vs Upper + Middle) & 1.231 (0.694-2.182) & 0.4777 & & \\
\hline Pathologic M (MI vs M0) & $3.695(2.134-6.397)$ & $<0.000$ I & $2.296(1.247-4.225)$ & 0.0076 \\
\hline Pathologic N (N2-N3 vs N0-NI) & $2.066(1.182-3.610)$ & 0.0109 & & \\
\hline Pathologic T (T3-T4 vs TI-T2) & I.59I (0.992-2.55I) & 0.054 & & \\
\hline Grade (G3-G4 vs GI-G2) & $2.107(1.293-3.433)$ & 0.0028 & & \\
\hline Recurrence (Yes vs No) ${ }^{a}$ & $2.546(1.549-4.184)$ & $<0.0001$ & $2.184(1.298-3.672)$ & 0.0032 \\
\hline Tissue $\Delta / 33 p 53 / p 53$ ratio $(\geq 2.6470$ vs $<2.6470)$ & $4.496(2.742-7.375)$ & $<0.000$ I & $3.864(2.293-6.5 \mathrm{II})$ & $<0.0001$ \\
\hline Serum $\Delta 133 p 53 / p 53$ ratio $(\geq 2.9160$ vs $<2.9160)$ & $2.559(1.617-4.050)$ & $<0.0001$ & $2.503(1.465-4.276)$ & 0.0011 \\
\hline
\end{tabular}

Notes: ${ }^{2} 149$ of 180 patients with regular follow-up checks for recurrence after surgery. Univariate and multivariate Cox survival (Forward Stepwise Likelihood Ratio method) analyses were applied to assess the hazard ratios (HRs) and $P$ value. *Adjusting for age, gender, BMI, smoking history, tumor location, pathologic $M, N$ and $T$ stage, grade, recurrence, tissue $\Delta 133 \mathrm{p} 53 / \mathrm{p} 53$ ratio and serum $\Delta \mathrm{I} 33 \mathrm{p} 53 / \mathrm{p} 53$ ratio, respectively.

Table 4 Univariate and Multivariate Survival Analyses of PFS in Patients with ESCC

\begin{tabular}{|c|c|c|c|c|}
\hline & \multicolumn{2}{|l|}{ Univariate Analysis } & \multicolumn{2}{|c|}{ *Multivariate Analysis } \\
\hline & HR (95\% Cl) & $P$ value & HR (95\% Cl) & $P$ value \\
\hline Age $(\geq 60$ vs $<60)$ & $1.352(0.877-2.084)$ & 0.1717 & & \\
\hline Gender (Male vs Female) & $1.580(0.836-2.986)$ & 0.1589 & & \\
\hline $\mathrm{BMI}(\geq 24$ vs $<24)$ & $1.320(0.863-2.020)$ & 0.2009 & & \\
\hline Smoking history (Yes vs No) & $2.030(1.164-3.542)$ & 0.0127 & & \\
\hline Tumor location (Lower vs Upper + Middle) & $1.363(0.833-2.230)$ & 0.2173 & & \\
\hline Pathologic M (MI vs M0) & $2.638(1.522-4.574)$ & $<0.000$ I & $2.171(1.219-3.866)$ & 0.0085 \\
\hline Pathologic N (N2-N3 vs N0-NI) & $2.066(1.226-3.482)$ & 0.0065 & & \\
\hline Pathologic T (T3-T4 vs TI-T2) & $1.438(0.932-2.218)$ & 0.1007 & & \\
\hline Grade (G3-G4 vs GI-G2) & $1.835(1.180-2.853)$ & 0.0070 & & \\
\hline Recurrence (Yes vs No) ${ }^{a}$ & $6.760(4.138-|1.04|)$ & $<0.0001$ & $5.212(3.062-8.873)$ & $<0.0001$ \\
\hline Tissue $\Delta / 33 p 53 / p 53$ ratio $(\geq 2.6470$ vs $<2.6470)$ & $3.677(2.378-5.684)$ & $<0.0001$ & $2.283(1.387-3.760)$ & $<0.0001$ \\
\hline Serum $\Delta 133 p 53 / p 53$ ratio $(\geq 2.9160$ vs $<2.9160)$ & $4.735(3.038-7.379)$ & $<0.0001$ & $3.230(1.947-5.359)$ & $<0.0001$ \\
\hline
\end{tabular}

Notes: ${ }^{2} 149$ of 180 patients with regular follow-up checks for recurrence after surgery. Univariate and multivariate Cox survival (Forward Stepwise Likelihood Ratio method) analyses were applied to assess the hazard ratios (HRs) and $P$ value. *Adjusting for age, gender, BMI, smoking history, tumor location, pathologic $\mathrm{M}, \mathrm{N}$ and $\mathrm{T}$ stage, grade, recurrence, tissue $\Delta \mid 33 \mathrm{p} 53 / \mathrm{p} 53$ ratio and serum $\Delta \mid 33 \mathrm{p} 53 / \mathrm{p} 53$ ratio, respectively.

ESCC patients from healthy donors was 0.6798 (Sensitivity: 76.11\%; Specificity: 77.55\%, AUC $=0.8376$ ), which was also less than 2.9160 (Figure S4E). These results indicate the potential usefulness of serum $\Delta 133$ p53/FLp53 ratio as a prognostic predictor for ESCC and may also reflect recurrence risk in a real-time manner.

\section{Discussion}

This investigation provides the novel finding that the preoperative tissue abundance of $\Delta 133 \mathrm{p} 53$ as well as the $\Delta 133$ p53/FLp53 ratio were significantly elevated in recurrent ESCC patients compared with non-recurrent patients. This finding is consistent with previous reports that $\Delta 133 \mathrm{p} 53$ increases risk of cancer recurrence in breast ${ }^{18}$ and ovarian cancer. ${ }^{32}$ Furthermore, clinicopathological factor distribution analyses also revealed that $\Delta 133$ p53 and FLp53 expression, as well as the $\Delta 133$ p53/FLp53 ratio correlated significantly with TNM stage or recurrence state. Most importantly, the Kaplan-Meier curve revealed that increased tissue $\Delta 133 \mathrm{p} 53$ and $\Delta 133$ p53/FLp53 ratio and decreased FLp53 were correlated to worse OS and PFS in ESCC patients. Thus, $\Delta 133$ p53 may also play an oncogenic role in ESCC progression.

$\Delta 133$ p53 constituted an independent prognostic marker in patients with advanced serous ovarian cancer. ${ }^{32}$ In our 

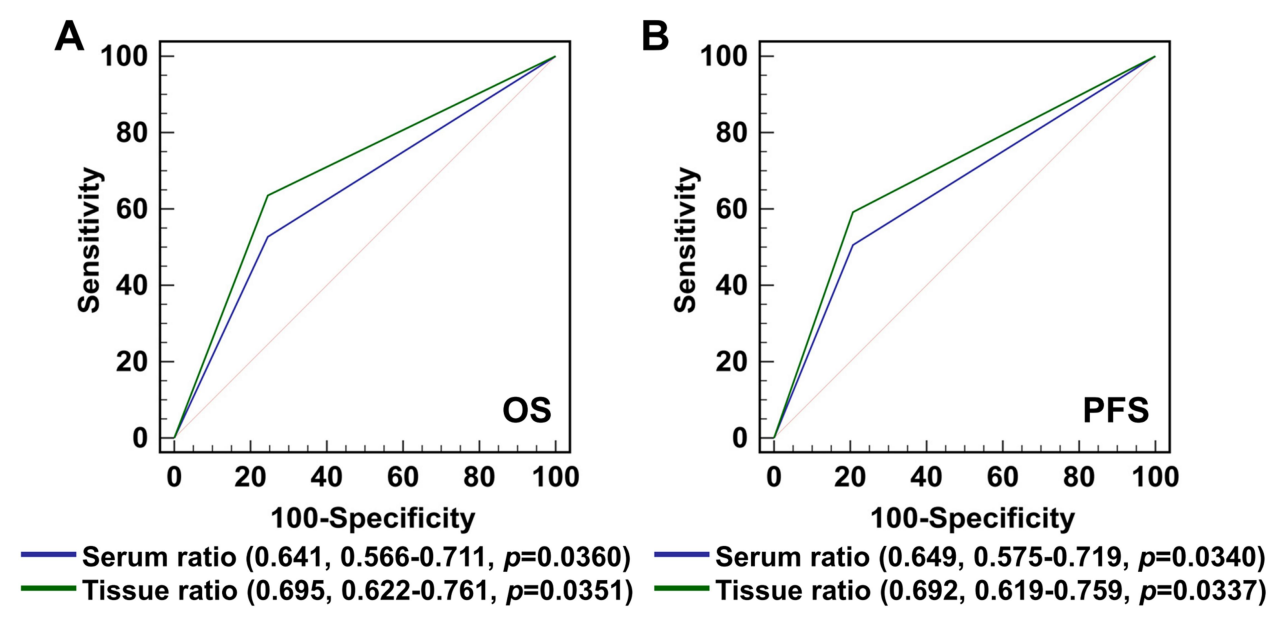

Figure 3 The ROC analysis of tissue and serum $\triangle 133$ p53/FLp53 ratio in Cox regression model. Patients were divided into two groups according to the cutoff value of tissue (2.6470) and serum (2.9160) $\Delta \mathrm{I} 33$ p53/FLp53 ratio, separately. (A) Receiver operating curve in the OS model. (B) Receiver operating curve in the PFS model.

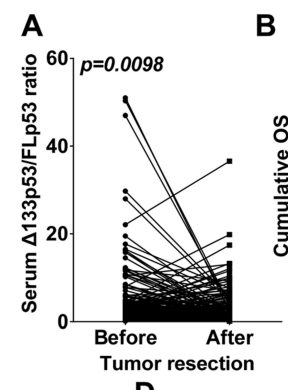

B

D

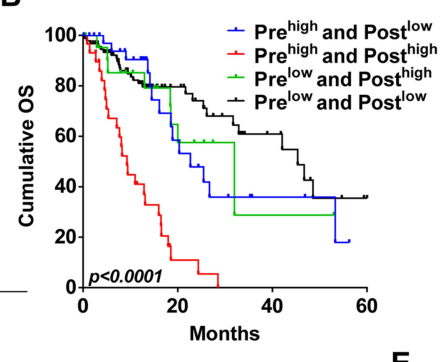

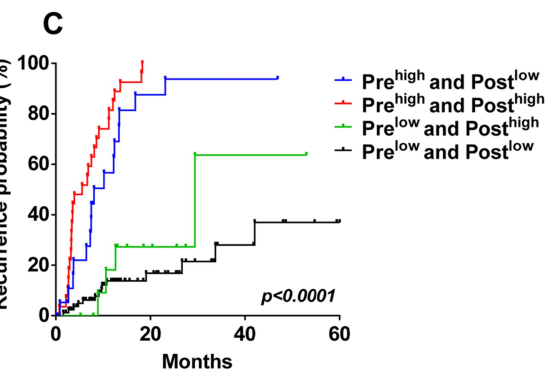

E

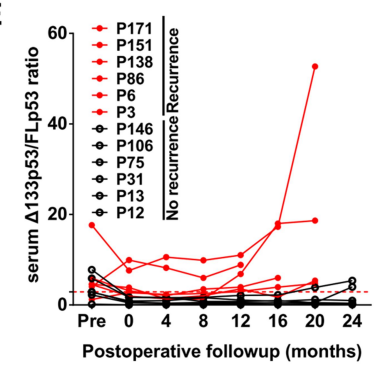

Figure 4 Dynamic changes of serum $\Delta \mathrm{I} 33 \mathrm{p} 53 / \mathrm{FL} 533$ ratio reflect treatment response and recurrence risk of ESCC. (A) Changes of serum $\Delta \mathrm{I} 33 \mathrm{p} 53 / \mathrm{FL} 533$ ratio before versus after (within $72 \mathrm{~h}$ following) resection. (B) OS of I80 ESCC patients divided by pre- and post-operative serum $\Delta$ I33p53/FLp53 ratio, cutoff value was 2.9160 . (C) Prognostic significance for time to recurrence in patients with persistent high serum $\Delta \mathrm{I} 33 \mathrm{p} 53 / \mathrm{FL} 53$ ratio, conversion of serum $\Delta \mathrm{I} 33 \mathrm{p} 53 / \mathrm{FL} 533$ ratio from high to low, conversion of serum $\Delta 133$ p53/FLp53 ratio from low to high, and persistent low (cutoff value was 2.9160). (D) PFS of I49 ESCC patients divided by pre- and post-operative serum $\Delta \mathrm{I} 33 \mathrm{p} 53 / \mathrm{FL} 53$ ratio, cutoff value was 2.9160 . (E) I 2 patients were monitored by CT scans every 4 months in a time range of 24 months, serum $\Delta \mathrm{I} 33 \mathrm{p} 53 / \mathrm{FLp} 53$ ratio were measured at each time until recurrence occurred. Dashed line means $Y=2.9160$.

study, tissue FLp53 and $\Delta 133$ p53/FLp53 ratio were shown to serve as independent prognostic factors for OS and PFS, while $\Delta 133$ p53 was not in a further univariate and multivariate analysis. Although we have previously confirmed that $\Delta 133 \mathrm{p} 53$ can act synergistically with $\mathrm{p} 73$ to upregulate the transcription of rad51, lig4 and $\operatorname{rad} 52$ by joining together to bind to a novel type of $\Delta 133 \mathrm{p} 53$-responsive element in their promoters, ${ }^{12,25}$ the detailed molecular mechanism of $\Delta 133 \mathrm{p} 53$ function is still unclear, the possibility of this inconsistency may result from the fact that
$\Delta 133$ p53 has three isoforms $(\alpha, \beta$ and $\gamma)$, which have been shown to have specific functions in a cancer or diseasespecific manner and could be regulated by different factors. ${ }^{18}$ As in breast cancer, $\Delta 133 p 53 \beta$ promotes cancer cell invasion and associates with cancer progression, while $\Delta 133 \mathrm{p} 53 \alpha$ and $\gamma$ are not. ${ }^{18}$ In human glioblastoma, the $\Delta 133$ p53 angiogenic effect is due to $\Delta 133$ p53 $\alpha$ and $\gamma$, but not the $\beta$ isoform. ${ }^{16}$ SRSF1, an essential splicing factor, promotes vascular smooth muscle cell (VSMC) proliferation and injury-induced neointima formation via 
inducing $\Delta 133 \mathrm{p} 53 \alpha$, but not the $\gamma$ and $\beta$ isoforms. ${ }^{33}$ It is worth noting that the expression level of SRSF1 differs among 33 cancer types as confirmed by Cancer Genome Atlas (TCGA) Program. The detailed roles of individual $\Delta 133 \mathrm{p} 53$ isoforms $(\alpha, \beta$ and $\gamma)$ and their functional molecular mechanisms should be investigated in future studies.

Circulating DNA/RNAs are not affected by tissue sampling timing and conditions, and thus are optimal diagnostic or prognostic biomarkers for various cancers, including ESCC. ${ }^{34,35}$ We previously reported that circulating RNAs could be used as diagnostic biomarkers for non-small cell lung carcinoma. ${ }^{27}$ In this investigation, we then further measured $\Delta 133$ p53 and FLp53 expression in serum samples by using $\mathrm{GAPDH}^{28}$ as an internal control. The Pearson's correlation coefficient of $\Delta 133 \mathrm{p} 53$ was 0.7019 between serum and tissue, significantly higher than that of FLp53 (r $=0.4030)$ and $\Delta 133 \mathrm{p} 53 /$ FLp53 ratio $(\mathrm{r}=0.4137)$, which indicated that cancer cells may be the main source of $\Delta 133$ p53. $\Delta 133$ p53 is significantly increased during the progression from premalignant adenoma to malignant carcinoma. ${ }^{36}$ Similar to results obtained from tissue samples, the serum abundance of $\Delta 133 \mathrm{p} 53$ as well as the $\Delta 133 \mathrm{p} 53 /$ FLp53 ratio were significantly increased in recurrent ESCC patients, and were related to TNM stage and recurrence state. Although serum $\Delta 133 \mathrm{p} 53$ showed no prognostic value in ESCC patients, the $\Delta 133$ p53/FLp53 ratio showed a better prognostic performance than FLp53 alone for OS $\left(\chi^{2}\right.$ value, 17.26 vs 5.80) and PFS ( $\chi^{2}$ value, 56.16 vs 10.27) prediction. Furthermore, ROC analysis revealed that prognostic performance of the serum $\Delta 133$ p53/FLp53 ratio showed no statistical difference from the tissue ratio, both of which were confirmed to be independent prognostic biomarkers for OS and PFS in multivariate analysis.

The clinical utility of monitoring circulating DNA/RNA changes with treatment and recurrence has been reported in various types of cancers. ${ }^{37,38}$ In this study, we reported for the first time that a significant decrease of serum $\Delta 133 \mathrm{p} 53$ / FLp53 ratio was observed soon after resection, which may well be attributed to surgical resection of the primary tumor. Patients with consistently high serum $\Delta 133$ p53/FLp53 ratio (higher than 2.9160 before and after surgery) showed increased recurrence rate and shorter TTR than those with postoperatively or consistently low levels. Furthermore, serum $\Delta 133$ p53/FLp53 ratios were higher than 2.9160 and even increased prior to the time of radiologically detected recurrence. Based on these results, we propose that serum $\Delta 133$ p53/FLp53 ratio may be a real-time surrogate indicator for treatment response and recurrence risk following the ESCC curative resection.

\section{Conclusions}

In summary, the results of this study demonstrate that preoperative high serum or tissue $\Delta 133$ p53/FLp53 ratio are independent prognostic factors for OS or PFS in ESCC patients undergoing curative resection. Serum $\Delta 133$ p53/FLp53 ratio in ESCC patients was significantly decreased within $72 \mathrm{~h}$ post tumor resection and patients with a consistently high serum $\Delta 133$ p53/FLp53 ratio ( $\geq 2.9160$ ) (pre- and post-operative) had higher recurrence rates than those with consistently low ratio values. In addition, dynamic detection at each follow-up timepoint showed that serum $\Delta 133$ p53/FLp53 ratios were increased upon radiologically detected progression. Thus, the serum $\Delta 133$ p53/FLp53 ratio can be a novel predictor for survival outcome and may serve as a real-time parameter for monitoring recurrence in ESCC patients after surgery.

\section{Abbreviations}

ESCC, esophageal squamous cell carcinoma; FLp53, fulllength p53; OS, overall survival; PFS, progression-free survival; ROC, receiver-operating characteristic curve; CNAs, copy number alterations; TTR, time to relapse; VSMC, vascular smooth muscle cell.

\section{Data Sharing Statement}

We are willing to share anonymized data after required ethical approval by the Ethics Committee of Central Hospital of Enshi Autonomous Prefecture.

\section{Ethics Approval and Informed Consent}

The study was approved by the Ethics Committee of Central Hospital of Enshi Autonomous Prefecture. All participants were informed about the purpose, procedures, benefits and potential risks of the study, and their written or oral consents were obtained. All procedures followed were in accordance with the ethical standards of the responsible committee on human experimentation (institutional and national) and with the Helsinki Declaration of 1964 and later versions.

\section{Funding}

This work was supported by National Natural Science Foundation of China (grant No. 81760540). This work 
was also funded by Natural Science Foundation of Hubei Province, China (2018CFB164), and Natural Science Foundation of Health and Family Planning Commission of Wuhan Municipality (WX18Q03, WX18Q27).

\section{Disclosure}

The authors report no conflicts of interest for this work.

\section{References}

1. Chen W, Zheng R, Baade PD, et al. Cancer statistics in China, 2015. CA Cancer J Clin. 2016;66(2):115-132. doi:10.3322/caac.21338

2. Deng J, Chen H, Zhou D, et al. Comparative genomic analysis of esophageal squamous cell carcinoma between Asian and Caucasian patient populations. Nat Commun. 2017;8(1):1533. doi:10.1038/ s41467-017-01730-x

3. Mariette C, Markar SR, Dabakuyo-Yonli TS, et al. Hybrid minimally invasive esophagectomy for esophageal cancer. $N$ Engl $\mathrm{J}$ Med. 2019;380(2):152-162. doi:10.1056/NEJMoa1805101

4. Wu C, Li D, Jia W, et al. Genome-wide association study identifies common variants in SLC39A6 associated with length of survival in esophageal squamous-cell carcinoma. Nat Genet. 2013;45 (6):632-638. doi:10.1038/ng.2638

5. Ohashi S, Miyamoto S, Kikuchi O, Goto T, Amanuma Y, Muto M. Recent advances from basic and clinical studies of esophageal squamous cell carcinoma. Gastroenterology. 2015;149(7):1700-1715. doi:10.1053/j.gastro.2015.08.054

6. Hao JJ, Lin DC, Dinh HQ, et al. Spatial intratumoral heterogeneity and temporal clonal evolution in esophageal squamous cell carcinoma. Nat Genet. 2016;48(12):1500-1507. doi:10.1038/ng.3683

7. Song Y, Li L, Ou Y, et al. Identification of genomic alterations in oesophageal squamous cell cancer. Nature. 2014;509(7498):91-95. doi:10.1038/nature 13176

8. Lin DC, Hao JJ, Nagata Y, et al. Genomic and molecular characterization of esophageal squamous cell carcinoma. Nat Genet. 2014;46 (5):467-473. doi:10.1038/ng.2935

9. Gao YB, Chen ZL, Li JG, et al. Genetic landscape of esophageal squamous cell carcinoma. Nat Genet. 2014;46(10):1097-1102. doi:10.1038/ng.3076

10. Sawada G, Niida A, Uchi R, et al. Genomic landscape of esophageal squamous cell carcinoma in a Japanese population. Gastroenterology. 2016;150(5):1171-1182. doi:10.1053/j.gastro.2016.01.035

11. Bykov VJN, Eriksson SE, Bianchi J, Wiman KG. Targeting mutant p53 for efficient cancer therapy. Nat Rev Cancer. 2017;18:89. doi:10.1038/nrc.2017.109

12. Gong L, Gong H, Pan X, et al. p53 isoform $\Delta 113 \mathrm{p} 53 / \Delta 133 \mathrm{p} 53$ promotes DNA double-strand break repair to protect cell from death and senescence in response to DNA damage. Cell Res. 2015;25(3):351-369. doi:10.1038/cr.2015.22

13. Candeias MM, Hagiwara M, Matsuda M. Cancer-specific mutations in $\mathrm{p} 53$ induce the translation of $\triangle 160 \mathrm{p} 53$ promoting tumorigenesis. EMBO Rep. 2016;17(11):1542-1551. doi:10.15252/embr.201541956

14. Mondal AM, Zhou H, Horikawa I, et al. $\Delta 133 \mathrm{p} 53 \alpha$, a natural $\mathrm{p} 53$ isoform, contributes to conditional reprogramming and long-term proliferation of primary epithelial cells. Cell Death Dis. 2018;9 (7):750. doi:10.1038/s41419-018-0767-7

15. Gong L, Pan X, Chen H, et al. $\mathrm{p} 53$ isoform $\Delta 133 \mathrm{p} 53$ promotes efficiency of induced pluripotent stem cells and ensures genomic integrity during reprogramming. Sci Rep. 2016;6:37281. doi:10.1038/srep37281

16. Bernard H, Garmy-Susini B, Ainaoui N, et al. The p53 isoform, $\Delta 133 p 53$ alpha, stimulates angiogenesis and tumour progression. Oncogene. 2013;32(17):2150-2160. doi:10.1038/onc.2012.242
17. Roth I, Campbell H, Rubio C, et al. The $\Delta 133 \mathrm{p} 53$ isoform and its mouse analogue Delta122p53 promote invasion and metastasis involving pro-inflammatory molecules interleukin-6 and CCL2. Oncogene. 2016;35(38):4981-4989. doi:10.1038/onc.2016.45

18. Gadea G, Arsic N, Fernandes K, et al. TP53 drives invasion through expression of its $\Delta 133$ p53beta variant. eLife. 2016;5:e14734. doi: $10.7554 /$ eLife. 14734

19. Lei J, Qi R, Tang Y, et al. Conformational stability and dynamics of the cancer-associated isoform $\triangle 133 \mathrm{p} 53 \beta$ are modulated by $\mathrm{p} 53$ peptides and p53-specific DNA. FASEB J. 2019;33(3):4225-4235. doi:10.1096/fj.201801973R

20. Arsic N, Gadea G, Lagerqvist EL, et al. The p53 isoform $\Delta 133 \mathrm{p} 53 \beta$ promotes cancer stem cell potential. Stem Cell Rep. 2015;4 (4):531-540. doi:10.1016/j.stemcr.2015.02.001

21. Kazantseva M, Eiholzer RA, Mehta S, et al. Elevation of the TP53 isoform $\Delta 133 \mathrm{p} 53 \beta$ in glioblastomas: an alternative to mutant $\mathrm{p} 53$ in promoting tumor development. $J$ Pathol. 2018;246(1):77-88. doi:10.1002/path.5111

22. Campbell H, Fleming N, Roth I, et al. 133p53 isoform promotes tumour invasion and metastasis via interleukin- 6 activation of JAK-STAT and RhoA-ROCK signalling. Nat Commun. 2018;9 (1):254. doi:10.1038/s41467-017-02408-0

23. Kastenhuber ER, Lowe SW. Putting p53 in context. Cell. 2017;170 (6):1062-1078. doi:10.1016/j.cell.2017.08.028

24. Aoubala M, Murray-Zmijewski F, Khoury MP, et al. p53 directly transactivates $\Delta 133 \mathrm{p} 53 \alpha$, regulating cell fate outcome in response to DNA damage. Cell Death Differ. 2011;18(2):248-258. doi:10.1038/ cdd.2010.91

25. Gong $\mathrm{H}$, Zhang Y, Jiang $\mathrm{K}$, et al. p73 coordinates with $\Delta 133 \mathrm{p} 53$ to promote DNA double-strand break repair. Cell Death Differ. 2018;25 (6):1063-1079. doi:10.1038/s41418-018-0085-8

26. Hu ZY, Xie N, Tian C, et al. Identifying circulating tumor DNA mutation profiles in metastatic breast cancer patients with multiline resistance. E Bio Medicine. 2018;32:111-118. doi:10.1016/j.ebiom.2018.05.015

27. Luo CL, Xu ZG, Chen H, et al. LncRNAs and EGFRvIII sequestered in TEPs enable blood-based NSCLC diagnosis. Cancer Manag Res. 2018;10:1449-1459. doi:10.2147/CMAR.S164227

28. Li Y, Elashoff D, Oh M, et al. Serum circulating human mRNA profiling and its utility for oral cancer detection. $J$ clin oncol. 2006;24(11):1754-1760. doi:10.1200/JCO.2005.03.7598

29. Camp RL, Dolled-Filhart M, Rimm DL. X-Tile. Clin Cancer Res. 2004;10(21):7252-7259. doi:10.1158/1078-0432.CCR-04-0713

30. Marcel V, Dichtel-Danjoy ML, Sagne C, et al. Biological functions of p53 isoforms through evolution: lessons from animal and cellular models. Cell Death Differ. 2011;18(12):1815-1824. doi:10.1038/cdd.2011.120

31. Vandekerkhove G, Todenhofer T, Annala M, et al. Circulating tumor DNA reveals clinically actionable somatic genome of metastatic bladder cancer. Clin Cancer Res. 2017;23(21):6487-6497. doi:10.1158/1078-0432.CCR-17-1140

32. Hofstetter G, Berger A, Schuster E, et al. $\Delta 133 \mathrm{p} 53$ is an independent prognostic marker in p53 mutant advanced serous ovarian cancer. $\mathrm{Br}$ J Cancer. 2011;105(10):1593-1599. doi:10.1038/bjc.2011.433

33. Xie N, Chen M, Dai R, et al. SRSF1 promotes vascular smooth muscle cell proliferation through a $\Delta 133$ p53/EGR1/KLF5 pathway. Nat Commun. 2017;8:16016. doi:10.1038/ncomms 16016

34. Hsu FM, Cheng JCH, Chang YL, Lee JM, Koong AC, Chuang EY. Circulating mRNA profiling in esophageal squamous cell carcinoma identifies FAM84B as a biomarker in predicting pathological response to neoadjuvant chemoradiation. Sci Rep. 2015;5:10291. doi:10.1038/srep10291

35. Jin Z, Olaru A, Yang J, et al. Hypermethylation of tachykinin-1 is a potential biomarker in human esophageal cancer. Clin Cancer Res. 2007;13(21):6293-6300. doi:10.1158/1078-0432.CCR-07-0818

36. Fujita K, Mondal AM, Horikawa I, et al. p53 isoforms $\Delta 133 \mathrm{p} 53$ and p53beta are endogenous regulators of replicative cellular senescence. Nat Cell Biol. 2009;11(9):1135-1142. doi:10.1038/ncb1928 
37. Liu Z, Jiang M, Zhao J, Ju H. Circulating tumor cells in perioperative esophageal cancer patients: quantitative assay system and potential clinical utility. Clin Cancer Res. 2007;13(10):2992-2997. doi:10.11 58/1078-0432.CCR-06-2072
38. Khan KH, Cunningham D, Werner B, et al. Longitudinal liquid biopsy and mathematical modeling of clonal evolution forecast time to treatment failure in the prospect-c phase II colorectal cancer clinical trial. Cancer Discov. 2018;8(10):1270-1285. doi:10.1158/2159-8290.CD-17-0891

\section{Publish your work in this journal}

Cancer Management and Research is an international, peer-reviewed open access journal focusing on cancer research and the optimal use of preventative and integrated treatment interventions to achieve improved outcomes, enhanced survival and quality of life for the cancer patient.
The manuscript management system is completely online and includes a very quick and fair peer-review system, which is all easy to use. Visit http://www.dovepress.com/testimonials.php to read real quotes from published authors. 